\title{
The Experiment of Dynamic Adsorption about Mahogany Sulfonate Ternary System in the Natural Sand packed tubular model
}

\author{
Tao-Ping CHEN ${ }^{1, a}$, Jun-Wei CHEN ${ }^{1, b}$, Zuo-An ZHANG $^{1, c}$ \\ ${ }^{1}$ The Key Laboratory of Enhancing Oil and Gas Recovery Efficiency of Educational Ministry, \\ Northeast Petroleum University, Daqing, Heilongjiang, China, 163318 \\ actp010@163.com, ${ }^{b} 171176051 @ q q . c o m,{ }^{c} 1261864469 @ q q . c o m$
}

\begin{abstract}
Keywords: Dynamic Adsorption, Interfacial Tension, Mahogany Sulfonate, Ternary Flood System. Abstract. Using Daqing natural sand packed tubular model, the length is $20 \mathrm{~cm}, 50 \mathrm{~cm}$ and $100 \mathrm{~cm}$, and the permeability was $(343 \sim 482) \times 10^{-3} \mu \mathrm{m}^{2}$, the injection rate is $1 \mathrm{~m} / \mathrm{d}$ and the experiment temperature is $45^{\circ} \mathrm{C}$, by the experiment of dynamic adsorption, studying the interfacial tension changes and viscosity changes of the produced liquid after weak alkali-mahogany sulfonate-polymer flood and absorb to the sand packed tubular model with oil or without oil. Experimental results show that: The mahogany sulfonate ternary system, under the condition of sand packed tubular model without oil, the adsorption makes the front of surfactant to migrate in the way of piston-like movement. When the residual oil exists or flows through a smaller distance $(0.2 \mathrm{~m})$, the adsorption makes the front of surfactant to migrate in the way of the non-piston-like movement; When the injection volume of the mahogany sulfonate ternary system reaches to $5.1 \sim 8.0 \mathrm{PV}$, the interfacial tension of produced liquid reaches to the ultra-low value, the quantity of dynamic saturated adsorption of mahogany sulfonate ternary system is $3.41 \sim 5.13 \mathrm{mg} / \mathrm{g}$; In the sand packed tubular model, after the injection PV of the mahogany sulfonate ternary system reaches to the 1 , the produced liquid flows stably in the outlet and contains polymer with a certain viscosity.
\end{abstract}

\section{Introduction}

Mahogany sulfonate is widely used in the tertiary oil recovery technology in China, the ternary system in the process of migrating in the reservoir, Mahogany sulfonate will happen to a certain degree of delayed outflow, one of the main reason is the surfactant is adsorbed in the reservoir, the adsorption results in the decrease of the surfactant concentration, causing the interfacial tension between the displacement liquid and the oil to increase out $10^{-3}$ orders of magnitude, and affecting oil displacement efficiency[1]. At present, there are many reports about the dynamic adsorption of surface active agent in reservoir cores and natural sand packed tubular model by measuring the concentration of the produced liquid[2]-[5], by changing the injection volume of compound system, the dynamic adsorption characteristics of surfactant in Daqing natural sand packed tubular model was studied, and simulated the relationship between the migration distance and the loss in the formation under different injection volume[2]. The core flow experiments were carried out in 8 cores which from the Daqing reservoirs, and the 4 oil displacement agents saturation retention and the retention with injection of 0.3 PV were measured[3]. By measuring the interfacial tension and viscosity of the produced liquid to study the dynamic adsorption of the surfactant is less. Selecting the Daqing natural core oil sands, which was filled with different length of sand packed tubular model, and then a certain number of PV mahogany sulfonate triad system was injected into, measuring interfacial tension and viscosity of the outlet, studying the mahogany sulfonate triad's dynamic adsorption and migration law in the sand packed tubular model with different length and oil or without oil. 


\section{Experimental Study}

The Main Instruments and Equipment. HBCD70 core displacement device of high temperature and high pressure, TX-500 interfacial tensiometer, Rs150 rheometer, constant pressure and constant speed pump, vacuum pump, metering pump, JJ-1 electric mixer, BS210S electronic balance, centrifugal glass tube with scale.

The Experimental Materials. Surfactant: Daqing mahogany sulfonate, at a concentration of $0.3 \%$; alkali: $\mathrm{Na}_{2} \mathrm{CO}_{3}$, at a concentration of $1.2 \%$; polymer: Daqing refining \& chemical company's production, molecular weight (700 950) $\times 10^{4}$, at a concentration of $2720 \mathrm{mg} / \mathrm{L}$; Experimental oil: Daqing fourth factory' simulation oil and the viscosity is $9 \mathrm{mPa} \cdot \mathrm{s}$; Water samples: Daqing fourth plants X2 test area reinjection water; Saturated water : simulating Daqing original formation water (salinity is $6778 \mathrm{mg} / \mathrm{L}$ ); Oil sands: Daqing Oilfield natural oil sands, washing, drying, screening; Sand packed tubular model parameters are shown in Tab. 1.

Tab. 1 Physical parameters of the sand packed tubular model

\begin{tabular}{cccccc}
\hline Number & $\begin{array}{c}\text { Length } \\
/ \mathrm{cm}\end{array}$ & $\begin{array}{c}\text { Diameter } \\
/ \mathrm{cm}\end{array}$ & $\begin{array}{c}\text { Porosity } \\
/ \%\end{array}$ & $\begin{array}{c}\text { Air permeability } \\
/ 10^{-3} \mu \mathrm{m}^{2}\end{array}$ & $\begin{array}{c}\text { Saturation of irreducible oil } \\
/ \%\end{array}$ \\
\hline 1 & 20 & 2.56 & 32.96 & 343.28 & 0 \\
2 & 50 & 2.335 & 36.94 & 358.26 & 0 \\
3 & 50 & 2.335 & 35.68 & 445.0 & 25.67 \\
4 & 100 & 2.335 & 36.86 & 482.0 & 0 \\
\hline
\end{tabular}

The Experimental Program. Oil-free dynamic adsorption model: a certain quality of filling sand was filled in sand packed tubular model, permeability measured, vacuum-pumping, and then saturated with water (calculated pore volume, porosity) and water permeability measured continuously injected mahogany sulfonate triad (molecular weight $(700 \sim 950) \times 10^{4}$ polymer 2720 $\mathrm{mg} / \mathrm{L}+$ Mahogany sulfonate surfactant $0.3 \%+\mathrm{Na}_{2} \mathrm{CO}_{3} 1.2 \%$ ), sampling the produced fluid continuous at a certain interval in the outlet. detecting the interfacial tension with the TX-500 interfacial tensiometer at $45^{\circ} \mathrm{C}$, while continuously recording the pressure gradient, until the produced liquid's interfacial tension tends to the original ternary system's interfacial tension.

Oil and oil-free model's dynamic adsorption is different, before adsorption test, oil model has to be saturated and then aging, water flooding to more than $98 \%$ of the moisture content, ternary driving $(0.3 \mathrm{PV}$ ternary $+0.2 \mathrm{PV}$ protection segment plug and subsequent water flooding to more than $98 \%$ of the moisture content).

\section{The Result and Analysis of the Experiment}

The Relationship Between Interfacial Tension of the Produced Liquid and the Ternary System Injection. According to the interfacial tension data of the produced fluid and the crude oil measured by TX-500 interfacial tensiometer, the curve of the produced liquid's interfacial tension of three length $(20 \mathrm{~cm}$ and $50 \mathrm{~cm}$ and $100 \mathrm{~cm})$ oil-free sand packed tubular model and the number of injection PV is shown in Fig. 1, the curve of the produced liquid's interfacial tension of containing residual oil sand packed tubular model $(50 \mathrm{~cm})$ and the injection of PV is shown in Fig. 2.

As can be seen from Fig. 1: The produced liquid of $20 \mathrm{~cm}$ in length sand packed tubular model 's interfacial tension changes relatively stable when the numbe of injection PV is $0 \sim 5.8$, and the value is relatively high, all of the mahogany sulfonate was adsorbed on the surface of the oil sands approximately, after the number of injection PV is 5.8, the interfacial tension decreases rapidly, mahogany sulfonate begins to flow out, the capacity of adsorption continues to increase, when the number of injection is $6.0 \mathrm{PV}$, and the interfacial tension reaches the state of ultra low, and with increase of the number of injection volume, the interfacial tension is stable and invariant, it can be considered when the injection volume of mahogany sulfonateis $6.0 \mathrm{PV}$, the amount of adsorption 
reaches the maximum, the saturated adsorption of this oil sands is $3.41 \mathrm{mg} / \mathrm{g}$ by the calculation. The produced liquid of $50 \mathrm{~cm}$ in length sand packed tubular model 's interfacial tension changes relatively stable when the numbe of injection PV is $0 \sim 5.1$, and the value is relatively high, all of the mahogany sulfonate was adsorbed on the surface of the oil sands approximately, after the number of injection PV is 5.1, the interfacial tension decreases rapidly, mahogany sulfonate begins to flow out, the capacity of adsorption continues to increase, when the number of injection is $5.3 \mathrm{PV}$, and the interfacial tension reaches the state of ultra low, and with increase of the number of injection volume, the interfacial tension is stable and invariant, it can be considered when the injection volume of mahogany sulfonate is 5.3 PV, the amount of adsorption reaches the maximum, the saturated adsorption of this oil sands is $3.52 \mathrm{mg} / \mathrm{g}$ by the calculation. The produced liquid of $100 \mathrm{~cm}$ in length sand packed tubular model 's interfacial tension changes relatively stable when the numbe of injection PV is $0 \sim 6.4$, and the value is relatively high, all of the mahogany sulfonate was adsorbed on the surface of the oil sands approximately, after the number of injection PV is 6.4, the interfacial tension decreases rapidly, mahogany sulfonate begins to flow out, the capacity of adsorption continues to increase, when the number of injection is $6.5 \mathrm{PV}$, and the interfacial tension reaches the state of ultra low , and with increase of the number of injection volume, the interfacial tension is stable and invariant, it can be considered when the injection volume of mahogany sulfonate is $6.5 \mathrm{PV}$, the amount of adsorption reaches the maximum, the saturated adsorption of this oil sands is $4.32 \mathrm{mg} / \mathrm{g}$ by the calculation.

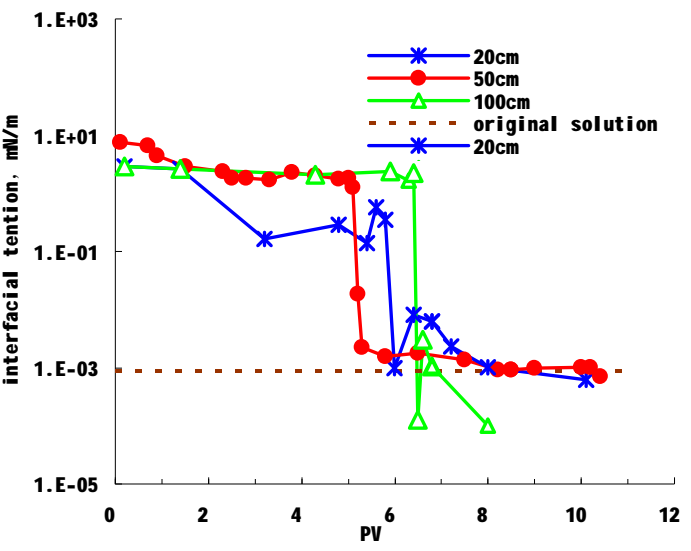

Fig.1 Relation of interfacial tension with the PV

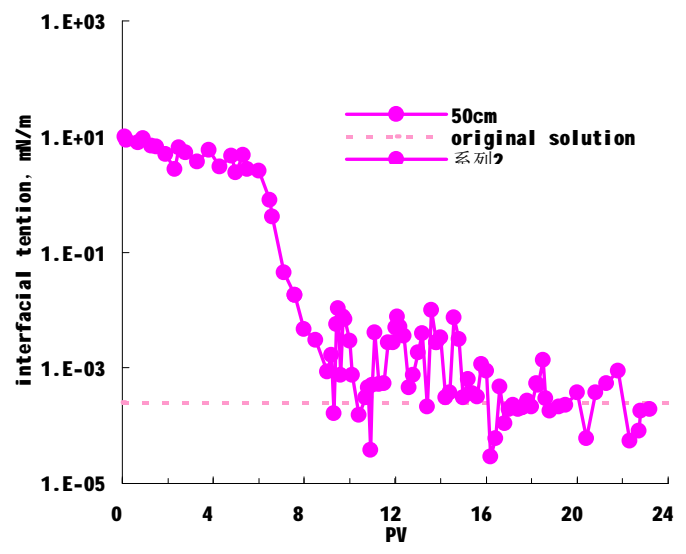

Fig.2 Relation of interfacial tension with the PV (with residual oil)

Thus it can be concluded that, under the condition that injection rate is $1 \mathrm{~m} / \mathrm{d}$, in a relatively short $(20 \mathrm{~cm})$ sand packed tubular model, the surfactanot is not full adsorbed in the oil sands when it arrives the outlet, the produced fluid in outlet has surfactanot when the oil sand does not reach to saturated adsorption, and the interface tension decreases; Before saturated adsorption of oil sands, the interfacial tension of the outlet fluid decreases to a relatively slow rate. And in longer $(50 \mathrm{~cm}$ and 100 $\mathrm{cm}$ ) sand packed tubular model, the surfactanot could be nearly full adsorbed in the oil sands when it arrives the outlet, the produced fluid in outlet almost has not surfactanot when the oil sand does not reach to saturated adsorption, interfacial tension is at a high level. Once the oil sand reaches saturation adsorption, the interfacial tension of the outlet fluid will suddenly drop to the ultra-low value, indicating that the surfactanot front is a piston type movement.

As can be seen from Fig. 2: the produced liquid of sand packed tubular model 's interfacial tension changes relatively stable when the numbe of injection PV is $0 \sim 6$, and the value is relatively high, all of the mahogany sulfonate was adsorbed on the surface of the oil sands approximately, after the number of injection PV is 6.0, the interfacial tension decreases rapidly, mahogany sulfonate begins to flow out, the capacity of adsorption continues to increase, when the number of injection PV is 8.0, and the interfacial tension reaches the state of ultra low, compared with the natural sand packed tubular model's adsorption experiment without residual oil, with the increase of the amount of injection, the interfacial tension is not stable, but fluctuates within a certain range of ultra-low state, this is due to the difference in the oil content of the produced liquid, which is causes the different content of the 
surfactant, it can be considered when the injection volume of mahogany sulfonate is $8.0 \mathrm{PV}$, the amount of adsorption reaches the maximum, the saturated adsorption of this oil sand is $5.13 \mathrm{mg} / \mathrm{g}$ by the calculation.

As can be seen from Fig. 1 and Fig. 2, by comparing the interfacial tension of produced liquid of sand packed tubular model with oil or not, the number of PV is 5.3 of the sand packed tubular model with oil and the PV is 8 of the sand packed tubular model without oil when the interfacial tension of the liquid drop to the ultra-low (reaching to saturation adsorption), and shows a non piston like movement; After the saturated adsorption, with the increase of the amount of injection, the interfacial tension is not stable, and fluctuates within a certain range of ultra-low state. This is due to the residual oil in the model continues to be driven out (Fig. 7), oil-water interface consumes a certain amount of surfactant.

The relationship between the produced liquid's viscosity and the ternary system injection. According to the data of produced fluid's viscosity measured by RS150 rheometer, the curve of the produced liquid's viscosity of three length $(20 \mathrm{~cm}$ and $50 \mathrm{~cm}$ and $100 \mathrm{~cm})$ oil-free sand packed tubular model and the number of injection PV is shown in Fig. 3, the curve of the corresponding differential pressure gradient and the number of injection PV is shown in Fig. 4, the curve of the produced fluid's viscosity of $50 \mathrm{~cm}$ in length sand packed tubular model with residual oil and the number of injection PV is shown in Fig. 5, the curve of the corresponding pressure gradient and the number of injection PV is shown in Fig. 6.

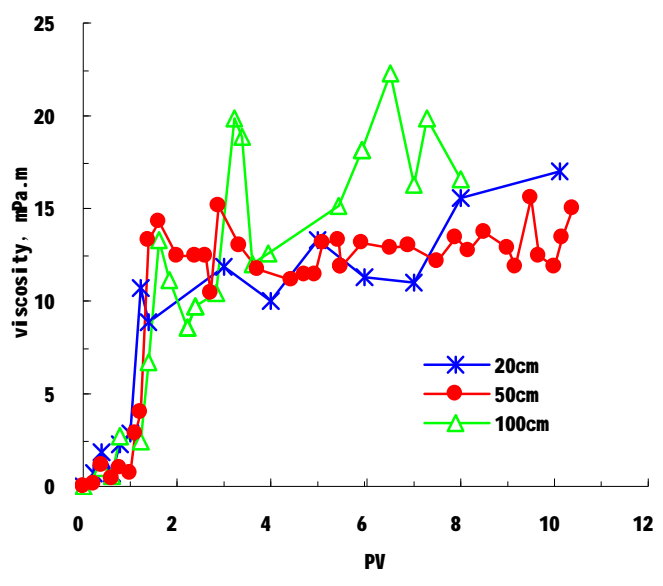

Fig. 3 Relation of the viscosity with the PV

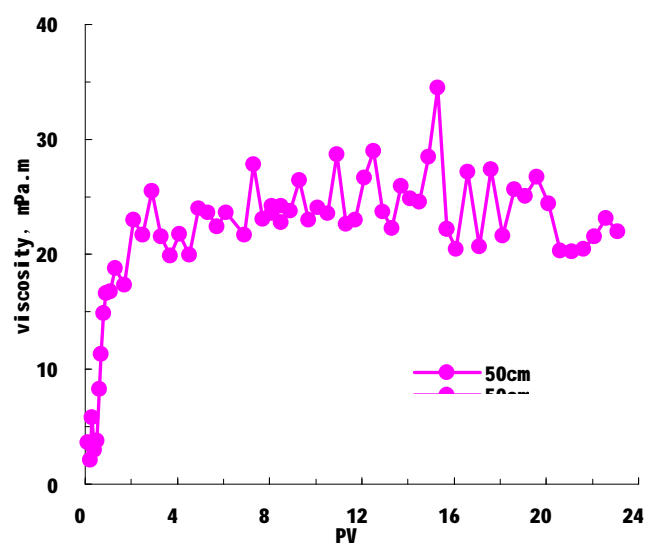

Fig. 5 Relation of the viscosity with the PV (with residual oil)

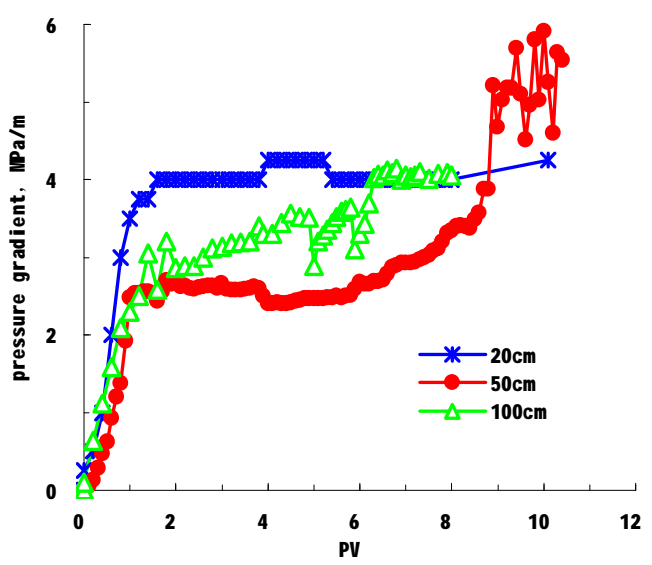

Fig. 4 Relation of the pressure gradient with the PV

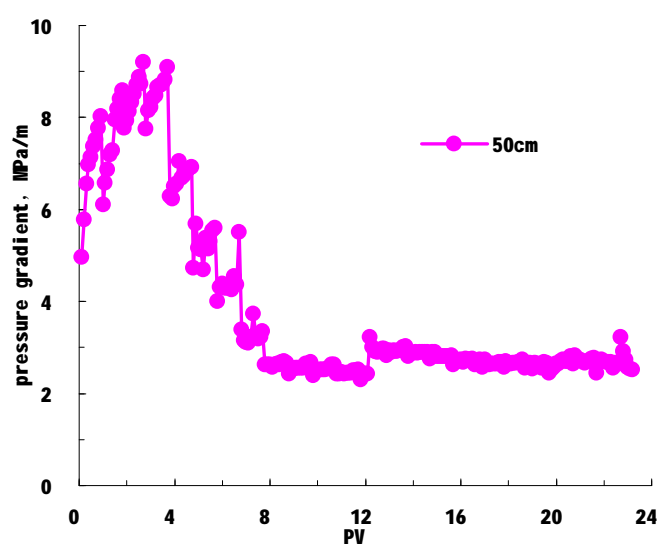

Fig. 6 Relation of the pressure gradient with the PV (with residual oil)

It can be seen from Fig. 3 that the viscosity of the produced fluid increases in the first and then tends to be stable with the increase of the number of injection PV. The produced fluid's viscosity changes flat relatively when the number of injection PV is below 1, when the number of injection PV is over 1 , the viscosity increases rapidly, the polymer begins to flow out, when the number of injection $\mathrm{PV}$ is 1.3 , the viscosity is stable with the increase of the amount of injection. 
It can be seen from Fig. 3 and Fig. 4, when the number of injection PV is small (0 6PV) relatively, the pressure gradient changes in the same way as the viscosity of the produced liquid; therefore, the pressure gradient could reflect changes of the viscosity of the produced fluid at a certain extent in real time in the experiment. When the amount of injection is large, due to the large amount of adsorption and retention of the polymer in the model, the pressure gradient increases continuously.

As can be seen from Fig. 5, the viscosity of produced fluid increases firstly and then stable with the number of injection of PV increase, and the viscosity of the produced liquid changes stable relatively when the number of injection PV is $0 \sim 0.5 \mathrm{PV}$, and the value is low relatively, after the number of injection PV is 0.5 , the viscosity increases rapidly, the polymer begins to flow out, when the number of injection PV is 2.1, the viscosity is stable basically with the increase of the amount of injection.

As can be seen from Fig. 5 and Fig. 6, the pressure gradient and the viscosity of produced liquid changes inconsistent in the sand packed tubular model with residual oil, the pressure gradient reflects mainly the flooding process of the residual oil in the model, the displacement pressure is relatively large when the amount of residual oil is more, and the displacement pressure is stable when the amount of residual oil is very little.

After the total oil recovery rate is $64.45 \%$ of the $50 \mathrm{~cm}$ in length sand packed tubular model with residual oil, and then the ternary system was injected continuously, Fig. 7 is the relationship between the oil production and the ternary system injection PV.

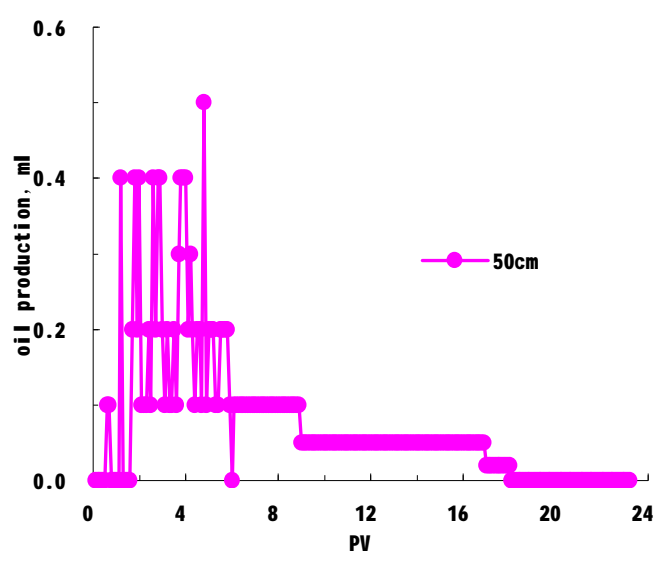

Fig.7 Relation of the oil production with the PV (the model with residual oil)

As can be seen from Fig. 7: Oil production is unstable when the number of injection PV is 0 6, fluctuating, and each sample has $0.1 \mathrm{ml}$ oil when the number of injection PV is 6 9, each sample has $0.05 \mathrm{ml}$ oil when the number of injection PV is 9 17, each sample has $0.02 \mathrm{ml}$ oil when the number of injection PV is 17 18. With the increase of the amount of injection, the residual saturation reduces gradually, the oil production decreases. The final ultimate recovery is $85.89 \%$.

\section{Conclusions}

The injection rate is $1 \mathrm{~m} / \mathrm{d}$, the mahogany sulfonate ternary system, under the condition of sand packed tubular model without oil, the adsorption makes the front of surfactant to migrate in the way of piston-like movement. When the residual oil exists or flows through a smaller distance $(0.2 \mathrm{~m})$, the adsorption makes the front of surfactant to migrate in the way of the non-piston-like movement.

When the injection volume of the mahogany sulfonate ternary system reachs to $5.1 \sim 8.0 \mathrm{PV}$, the interfacial tension of produced liquid reaches to the ultra-low value, the quantity of dynamic saturated adsorption of mahogany sulfonate ternary system is $3.41 \sim 5.13 \mathrm{mg} / \mathrm{g}$.

In the sand packed tubular model, after the injection PV of the mahogany sulfonate ternary system reaches to the 1 , the produced liquid flows stably in the outlet and contains polymer with a certain viscosity. 


\section{References}

[1] Dao-shan Li, Guangzhi Liao, Qing Jia, etc. A Study on Component Retention in Reservoirs during APS Flooding Field Trials at Daqing [J]. Oilfield Chemistry, 2001, 17 (4) : 362-366.

[2] Jirui Hou, Shufen Zhang, Jinzong Yang, et al. Chemical Agent Loss and Effective Distance of Ultra Low IFT in APS Flooding [J]. Journal of Dalian University of Technology, 2005,45 (4): 496-500.

[3] Wenmeng Duan. Study on Adsorption and Retention of Oil Displacement Agents in ASP Flooding [D]. Southwest Petroleum Institute, 2002.

[4] Fang Yu, Weiyu Fan, Youzhi Duan, et al. Study on Adsorption of NPS Petroleum Sulfonate on Gudao Reservoir Sand [J]. Oilfield Chemistry, 2007, 24 (4): 347-350.

[5] Hongyan Wang, Xulong Cao, Jichao Zhang, et al. Dynamic Adsorption of Flooding System Comprising Shengli Petroleum Sulfonate [J]. Advances in Fine Petrochemicals.2005,6 (3): 28-32. 